Article

\title{
Benefit Assessment of Skidder Powertrain Hybridization Utilizing a Novel Cascade Optimization Algorithm
}

\author{
Juraj Karlušić ${ }^{1}$, Mihael Cipek ${ }^{1, *(1)}$, Danijel Pavković ${ }^{1}$, Željko Šitum $^{1}$, Juraj Benić ${ }^{1}$ (I) \\ and Marijan Šušnjar ${ }^{2}$ \\ 1 Department of Robotics and Production System Automation, Faculty of Mechanical Engineering and Naval \\ Architecture, University of Zagreb, 10000 Zagreb, Croatia; juraj.karlusic@fsb.hr (J.K.); \\ danijel.pavkovic@fsb.hr (D.P.); zeljko.situm@fsb.hr (Ž.Š.); juraj.benic@fsb.hr (J.B.) \\ 2 Faculty of Forestry, Forest Engineering Institute, University of Zagreb, 10000 Zagreb, Croatia; \\ msusnjar@sumfak.hr \\ * Correspondence: mihael.cipek@fsb.hr
}

Received: 9 November 2020; Accepted: 10 December 2020; Published: 12 December 2020

\begin{abstract}
Over the last decade, off-road vehicles have been increasingly hybridized through powertrain electrification in terms of additional electrical machine-based propulsion and battery energy storage, with the goal of achieving significant gains in fuel economy and reductions in greenhouse gases emissions. Since hybrid powertrains consist of two or more different energy sources and may be arranged in many different configurations, there are many open questions in their design and powertrain energy management control, which may have influence on the hybridized powertrain purchase cost and efficiency. This paper presents simple backward optimization models of conventional and hybrid cable skidder powertrains. These models are then used in the optimization of control variables over one forest path in order to find the minimum possible fuel consumption. The optimization results show that $15 \%$ fuel efficiency improvement in winching and skid trail driving can be achieved with the selected hybrid powertrain. With that improvement, main hybrid drive components can be paid off in 13 years.
\end{abstract}

Keywords: skidder; optimization; hybrid drive; fuel consumption

\section{Introduction}

Agriculture and forestry are responsible for about six percent of the greenhouse gases (GHG) shares in the EU-27 countries [1], with transportation in harvesting operations having the greatest environmental impact, with fuel consumption being mostly comparable to expenditures of other resources (motor and hydraulic oil, tires, maintenance, etc.) consumed during these operations [2].

In order to satisfy the proposed goals for reduction of GHG and other harmful gasses, manufacturers are constantly innovating. The most prominent way of innovating with the aim of reducing emissions is through hybridization and electrification of the driveline, which is also becoming commonplace in the forestry sector, with various machinery, mostly harvesters [3], showing promising results in terms of fuel savings, lower running costs, and noise level reduction. Hybrid skidders are not yet available on the market, nor has their hybridization been researched in many publications. This presents the main motivation for doing this research. As skidders are essentially specialized forestry tractors equipped with a log pulling winch and other mechanical accessories necessary for logging, modernization efforts applicable to similar off-road vehicles can also be applied to skidders. Many different hybrid powertrain variants can be found in off-road vehicle, such as fuel cell hybrids [4], 
hybrid electric vehicles with natural gas compression engines [5], and a single electric machine power-split hybrid [6].

According to [1], the average age of non-road mobile machinery (NRMM) used in agriculture and forestry is over 15 years. These vehicles are rather expensive due to their specialized purpose, so their owners and operators are not likely to purchase a new vehicle, hybrid or electric, due to their high purchase (initial investment) cost, especially if hybridization through retrofitting might be a much less expensive solution to satisfying the reduced emissions and fuel (energy) expenditure constraints.

In that regard, hybridization through retrofitting of existing vehicle powertrains may indeed be a more palatable solution for off-road machinery operators, because it allows for three main advantages compared to traditional vehicles: (i) reduction of harmful particles and gasses, (ii) improved driving performance, and (iii) lower fuel consumption. However, it is paramount to first understand the vehicle purpose and its driving modes to correctly choose a proper hybrid powertrain configuration and, thus, to offer a suitable design of hybridized vehicle powertrains [7]. To get the most out of the hybrid vehicle, it is also crucial to have an efficient control strategy that will manage power flows between different energy sources (i.e., the internal combustion engine, electrical machines, and the energy storage systems, such as a battery).

In order to gain these insights, and to find an off-line optimal control law for the hybrid powertrain, this paper proposes the utilization of optimization tools based on the so-called cascade control optimization algorithm [8], featuring a simplified backward-looking model of the hybrid powertrain. The main hypothesis of this work is that by utilizing the combined approach based on successive optimization by means of dynamic programming (DP) and a back propagation through time (BPTT) gradient-based algorithm, a noticeable improvement in fuel efficiency and greenhouse gases emission can be achieved, compared to the rule-based control previously presented in [9]. Based on the results of the optimization study conducted herein, conclusions are drawn regarding the potentials for emission reduction and overall fuel (energy) efficiency improvement of hybridized powertrains in a forestry machinery application, along with the estimation of the return of investment period of such a hybridization.

\section{Skidder Models Used in Optimization}

Simple backward models of conventional and hybrid skidders used for simulation studies were introduced in [9]. The models are based on a $7200 \mathrm{~kg}$ Skidder EcoTrac 120V, which is a heavy-duty forestry tractor used for pulling logs out of forests. It is manufactured by the Hittner company located in the town of Bjelovar, Croatia [10]. According to the data from reference [11], over a hundred units of this type are deployed around different forestry estates in Croatia.

Figure 1a shows the main components of a conventional skidder powertrain. The system consists of internal combustion engine (ICE), friction clutches, a ten-speed manual gearbox divided in five low-ratio road transport gears, and five high-ratio working gears, mechanical shafts that transfer power to forward (FD) and rear (RD) differentials and distribute power to all four wheels [12]. The ICE considered herein is a four-stroke diesel engine type F6L-914, manufactured by Deutz AG from Köln, Germany. It is a naturally-aspirated $6.5 \mathrm{~L}$ six-cylinder in-line (straight-six), air-cooled, engine with maximum power rating $P_{e}$ of $84 \mathrm{~kW}$ at $2300 \mathrm{~min}^{-1}$ and maximum engine torque $T_{e}$ of $400 \mathrm{Nm}$ at $1500 \mathrm{~min}^{-1}$ [13]. Skidders are also equipped with a double (or single) drum winch used for pulling logs, and a rear-side anchor-protective board, which also provides additional stability during winching operations. In a conventional skidder, the aforementioned winch system is driven by a hydraulic pump propelled by mechanical power from the engine, which may also supply additional hydraulic actuators.

The principal requirement of hybridization is maintaining the performance of the hybrid drive at least equal to that of the conventional one, while minimal modifications to the overall powertrain would also be desirable from a production point of view. In that respect, the maximum loading capabilities of the particular forestry vehicle should also be respected (see e.g., [14] and the discussion presented therein). A P2 parallel hybrid configuration (shown in Figure 1b) is proposed herein, which satisfies 
the predefined driving performance, and also does not require major modifications of the conventional powertrain for its installation [9]. Thus, the chosen P2 parallel configuration may also be convenient from the standpoint of conventional powertrain retrofitting to its hybrid counterpart. As Figure $1 \mathrm{~b}$ shows, the hybrid skidder has an additional electric motor-generator (MG), clutch, and properly sized battery to store sufficient electric energy for the anticipated working cycle. Since improved acceleration, driving comfort, and other requirements typical for passenger vehicles are not crucial for heavy-duty forestry vehicles, introduction of a hybrid powertrain is primarily motivated by the possibility of reduction of fuel consumption and pollutant emissions. In that respect, fuel savings can be achieved by implementing the so-called start-stop functionality, i.e., turning off the main diesel engine when the vehicle is stationary, and using the electric motor to propel the winch hydraulic pump. Other operating regimes, such as those characterized by peak engine torque requirements may also be partially covered by the electric machine torque, such as when hard accelerating and going uphill are necessary. In turn, this may further reduce the fuel consumption, especially if the energy stored within the battery has been obtained by operating the ICE in the vicinity of its fuel-optimal operating point, or during regenerative braking intervals (e.g., during vehicle downhill driving).

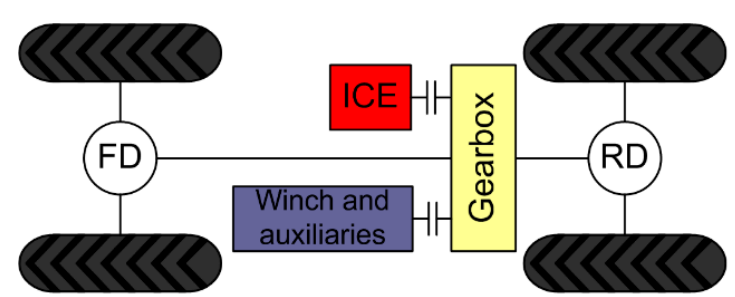

(a)

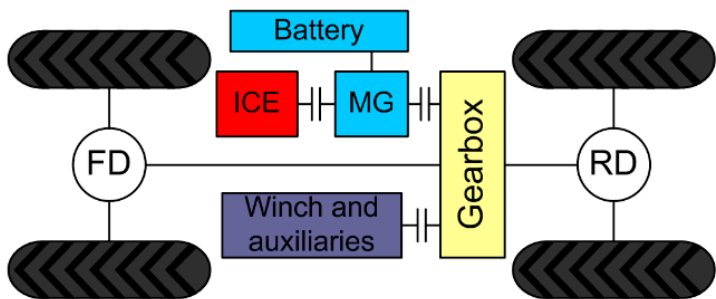

(b)

Figure 1. Simplified representation of conventional skidder (a) and the proposed hybrid vehicle configuration (b).

\subsection{Powertrain Model Components}

Detailed hybrid powertrain model components selection and sizing were conducted in [9]. The electric motor (MG) was chosen to propel the winch hydraulic system since the winch drive is the largest power consumer during stationary operation with the maximum load of $83 \mathrm{~kW}$ [9]. A three-phase synchronous permanent-magnet electrical machine (manufacturer designation AF 130) with nominal torque of $145 \mathrm{Nm}$ and nominal power of $64 \mathrm{~kW}$ was chosen in [15]. Its peak output power of $100 \mathrm{~kW}$ can be delivered for up to $60 \mathrm{~s}$, which is considered satisfactory for the particular application. Li-ion cells were chosen for the hypothetical battery energy storage system due to their availability and high gravimetric energy density. The number of cells required ( 250 cells in particular) was determined based on the electrical power requirements from [9]. In order to satisfy the rated DC bus voltage requirement of the servomotor power converter (typically $460 \mathrm{~V}$ ), cells were arranged in parallel-connected series strings, with 125 cells each, thus being able to deliver up to $100 \mathrm{~kW}$ from the battery energy storage system. Parameters (such as number $N$, energy $E$, charge capacity $Q$, power rating $P_{\max }$, and mass $m_{\text {bat }}$ ) of a single cell [16] and the proposed battery are given in Table 1.

Table 1. Cell and battery parameters.

\begin{tabular}{cccccc}
\hline & $\boldsymbol{N}(-)$ & $E(\mathbf{k W h})$ & $\boldsymbol{Q}(\mathbf{A h})$ & $\boldsymbol{P}_{\max }(\mathbf{k W})$ & $\boldsymbol{m}_{\text {bat }} \mathbf{( k g )}$ \\
\hline Cell & 1 & 0.06 & 15.9 & 0.4 & 0.63 \\
Battery & 250 & 15 & 31.8 & 100 & 157.2 \\
\hline
\end{tabular}

Figure 2 shows the static characteristics (maps) of individual components of the skidder hybrid powertrain from [9], which are based on engine catalog data from [13], and electric machine data from [15]. Battery data were taken from [16]. The characteristics include an internal combustion 
engine torque vs. engine speed map with specific fuel consumption as the parameter (Figure 2a), electric motor torque vs. speed map with efficiency as the parameter, shown in Figure $2 b$, and the battery cell open-circuit voltage vs. state-of-charge $(S o C)$, illustrated in Figure $2 c$, and cell internal resistance in Figure 2d. Green curves in Figure 2a,b denote the maximum torque curves for particular machines (i.e., internal combustion engine, $\mathrm{M} / \mathrm{G} 1$ and $\mathrm{M} / \mathrm{G} 2$ machines, respectively).
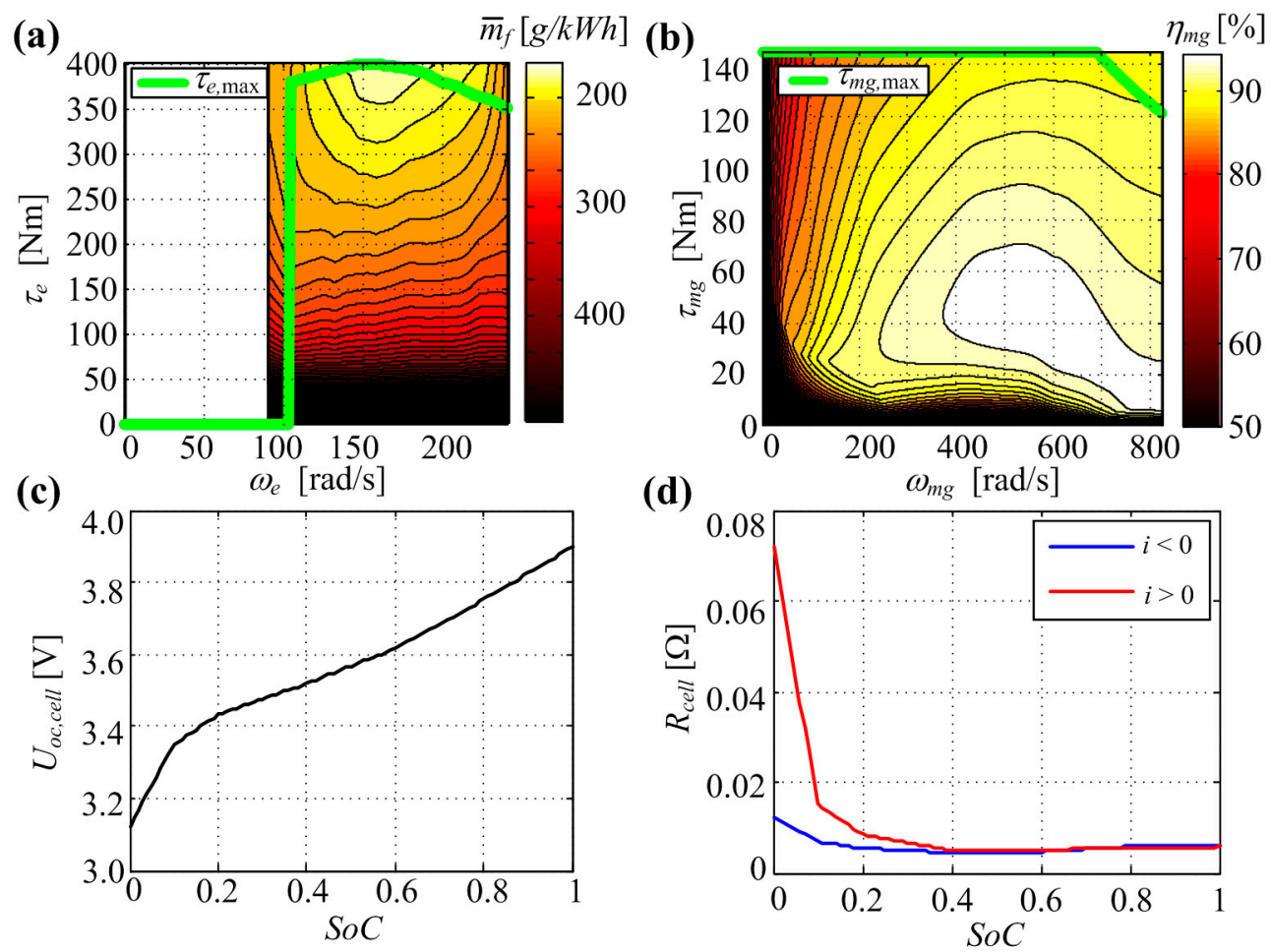

Figure 2. Static maps of engine (a), MG machine (b), cell voltage (c), and internal resistance (d).

Vehicle all-four-wheel traction is achieved through a ten-speed gearbox connected directly to the ICE, comprising five low-ratio and five high-ratio gears. High transmission ratio gears are particularly interesting for this study, because they are used as working gears in forest areas and as such are considered further in this paper. The total transmission ratios for each high-ratio gear setting, transfer case, and differentials are shown in Table 2.

Table 2. Selected gear variable and corresponding total ratios [9].

\begin{tabular}{cc}
\hline $\boldsymbol{s}_{\text {gear }}(-)$ & Total Gear Ratio, $\boldsymbol{h}_{\text {gear }} \mathbf{( - )}$ \\
\hline 1 & 213 \\
2 & 116 \\
3 & 70 \\
4 & 44 \\
5 & 29 \\
\hline
\end{tabular}

\subsection{Backward-Looking Powertrain Model}

In order to reduce the computational load of the optimization algorithm, the backward-looking model structure is commonly used in various optimization studies [7]. Figure 3 shows the structure of the hybrid skidder backward-looking model, wherein the vehicle wheel angular speed input $\omega_{L}$ is obtained from the vehicle longitudinal velocity $v$ (defined as time series for the considered driving cycle) according to the following straightforward relationship:

$$
\omega_{L}=\frac{v}{r}
$$


where $r$ is the effective tire radius.

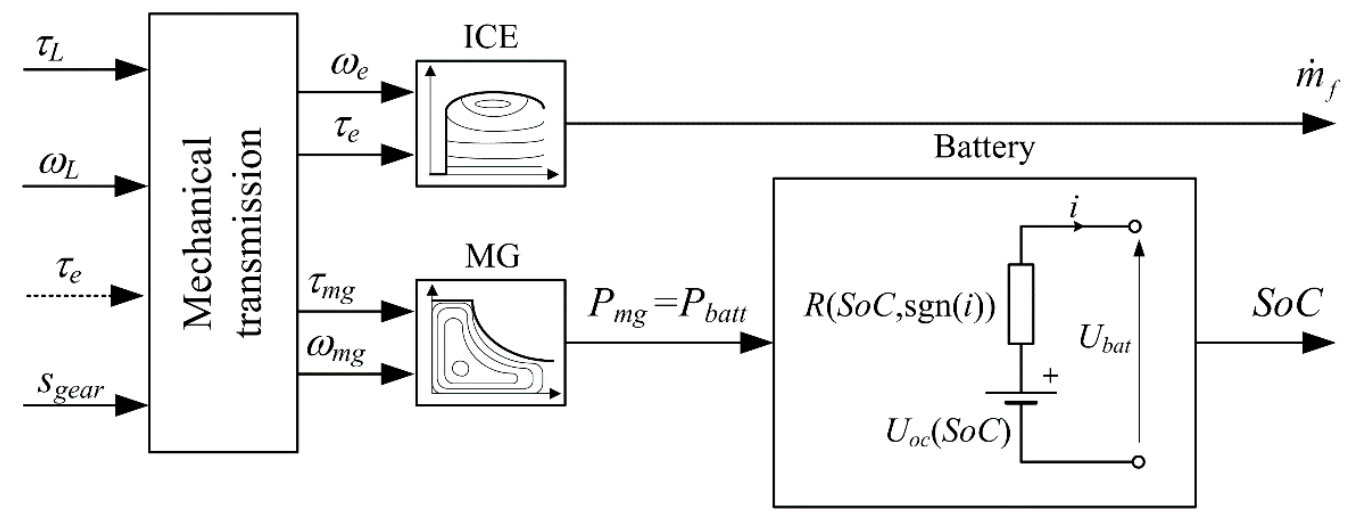

Figure 3. Block diagram of the hybrid skidder powertrain backward model.

On the other hand, the related transmission load torque $\tau_{L}$ is calculated by using the simplified skidder motion Equation [17]:

$$
\begin{gathered}
\tau_{L}=r F_{l}+\left(m_{l}+m_{s}\right) \dot{v}= \\
=r g\left\{\left[m_{l}(1-k) \mu_{p}+\left(m_{s}+k m_{l}\right) f\right] \cos (\alpha)+\left[m_{l}+m_{s}\right] \sin (\alpha)\right\}+\left(m_{l}+m_{s}\right) \dot{v},
\end{gathered}
$$

where $F_{l}$ is the total load force, $m_{l}$ is the winch-suspended log weight, $m_{s}$ is the skidder weight, $\alpha$ is the terrain slope, and $f, k$, and $\mu_{p}$ represent the rolling resistance, load mass distribution, and skidding resistance coefficients, respectively. Rolling resistance $f$ and skidding resistance $\mu_{p}$ are highly dependent on the varying state of the terrain (e.g., muddy, dry or wet ground, soil of rocky terrain). Within the scope of the work presented in this paper, median values $\left(f=0.12, k=0.48, \mu_{p}=0.51\right)$ from the field data [18] are used herein.

In this particular model, load torque $\tau_{L}$ and wheel speed $\omega_{L}$ are the a priori known model inputs. Other powertrain inputs $\tau_{e}$, and $s_{g e a r}$ are the ICE torque and the selected gear ratio, respectively, and they represent the control variables to be optimized. Note that in the case of conventional skidders only one discrete $s_{\text {gear }}$ variable is optimized. The mechanical transmission sub-model is described by the "inverted" kinematics equations for each gear as follows:

$$
\begin{gathered}
\omega_{m g}=\omega_{e}=\omega_{L} h_{\text {gear }}\left(s_{\text {gear }}\right), \\
\tau_{m g}+\tau_{e}=\frac{\tau_{L}}{h_{\text {gear }}\left(s_{\text {gear }}\right)},
\end{gathered}
$$

where in the case of a conventional skidder, the MG torque $\tau_{m g}$ and speed $\omega_{m g}$ are omitted from the above equations.

Referring further to Figure 3, the transmission sub-model output variables $\omega_{e}$ and $\tau_{e}$ are fed into the specific fuel consumption map shown in Figure 2a in order to calculate the engine fuel mass flow:

$$
\dot{m}_{f}\left(\tau_{e}, \omega_{e}\right)=\frac{\tau_{e} \omega_{e} \bar{m}_{f}\left(\tau_{e}, \omega_{e}\right)}{1000 \cdot 3600} .
$$

Similarly, the MG speed and torque variables are fed as inputs into the electric machine efficiency map in Figure $2 \mathrm{~b}$ in order to determine the MG electric power output $P_{m g}$ which is equal to the battery power $P_{\text {batt }}$ in the following way:

$$
P_{b a t t}=P_{m g}=\eta_{m g}^{k_{e f}} \omega_{m g} \tau_{m g}
$$


where $\eta_{m g}$ is the efficiency of the MG machine. The superscripts $k_{e f}$ is equal to -1 in the case of an electrical machine operating as a motor, while is it is equal to +1 in the case of generator operation.

The battery dynamics model is derived from the equivalent circuit shown in the battery block in Figure 3, with the following well-known nonlinear differential equation [19]:

$$
\frac{d S o C}{d t}=\frac{\sqrt{U_{o c}^{2}(S o C)-4 R(\operatorname{sgn}(i)) P_{b a t t}}-U_{o c}(S o C)}{2 Q_{\max } R(\operatorname{sgn}(i))},
$$

with $0 \leq S o C \leq 1$ being the battery state of charge, and $Q_{\max }$ being the battery charge capacity. Within the above battery model, the so-called open-circuit voltage $U_{o c}$ is made dependent on the $S o C$ (Figure 2c, [9]). The battery internal resistance $R$ is also made dependent on the $S o C$, with the additional dependence on the current sign, that is current flow direction denoting charging $(-1)$ and discharging $(+1)$, as shown in Figure 2d.

\subsection{Skidder Load Calculations}

In order to calculate the time-dependent load vectors $\left(\tau_{L}, \omega_{L}\right)$ from the skidder motion profile, a simple vehicle dynamics model including the transmission model, vehicle mass, and variable driveline load related to slope effects and timber pulling weight is proposed herein, and shown in Figure 4 . Reference velocity $v_{\text {ref }}$ is compared with actual skidder velocity $v$. Velocity difference is fed to the proportional gain term $\left(m_{l}+m_{s}\right)$ and the required wheel force $F_{w}$ is calculated. This force is subject to powertrain limitations, with positive values corresponding to limitations of the ICE engine, and negative values corresponding to limitations of the MG during regenerative braking. These limitations are modeled within the transmission force map as a lookup table. In the case when regenerative braking is not sufficient to provide enough braking force, brakes are activated, resulting in additional negative breaking force $F_{b}$. Skidder acceleration is than calculated from the sum of all forces acting upon the overall mass (i.e., wheel force $F_{w}$, load $F_{l}$, and breaking force $F_{b}$, see summation point in Figure 4). Since the skidder is represented as a point mass, its overall mass consists of the skidder mass itself $m_{s}$ and the log mass $m_{l}$.

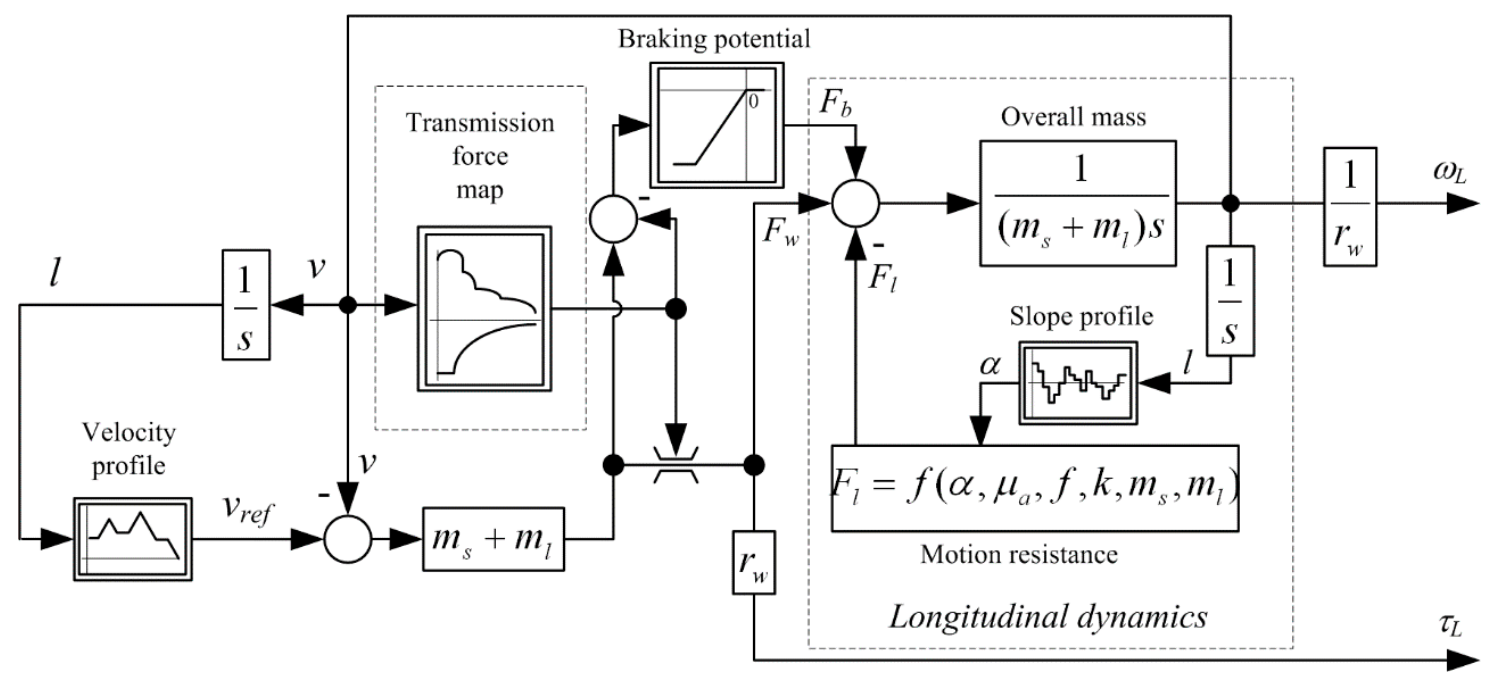

Figure 4. Block diagram of a simple transmission skidder model.

\section{Skidder Driving Missions and Load Calculations}

Based on an exhaustive literature review, there are no standardized driving cycles for skidders such as those available for road vehicles [20]. A skidder's working cycle can be divided into a skid trail phase, landing travel that consists of unloaded and loaded travel, landing and felling site work, and additional allowance time. Felling and landing site work contain forestry operations such as 
hooking, winching, unhooking, piling, etc. [21]. In reference [22] several skidder cycles were generated by using terrain data from internet services (Croatian forestry company „Hrvatske šume“, Zagreb, Croatia and "GPS Visualizer" free online software with last update from 24.2.2020., created by Adam Schneider, Portland, USA) that consisted of only skid trail travel and winching and known powertrain load parameters available from the literature. Hence, in this paper a single hillside slope from [9] was chosen for optimization studies, wherein the vehicle travels in both directions with three different hung loads: $0 \mathrm{t}, 3 \mathrm{t}$, and $6 \mathrm{t}$, with the latter being the maximum load of the winch [18]. The working cycle studied in this paper will also consist of only skid trail travel and winching. Without real terrain measurements it is impossible to assume skidder working conditions in the rest of the harvesting operations. This presented model can later be easily adjusted and used across the whole working cycle. The cycle studied in this paper presents over $50 \%$ of the skidder's working time [21] and can be used as a good representation of expected fuel savings.

Reference velocity is calculated by using the vehicle motion equation as the input to determine the ICE speed wherein maximum powertrain torque is achieved, along with the selection of the gear ratio that enables the skidder to haul the particular load. In the case of downhill drive, reference velocity is reduced in order to avoid dangerous overspeed operation of the drive. Considered driving missions

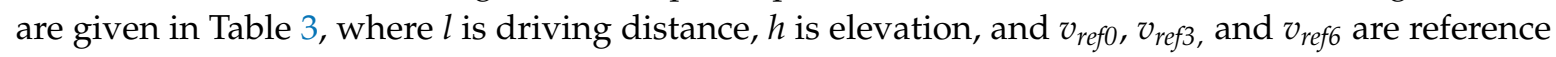
velocities for 0,3 , and $6 \mathrm{t}$ of load, respectively.

Table 3. Driving scenarios.

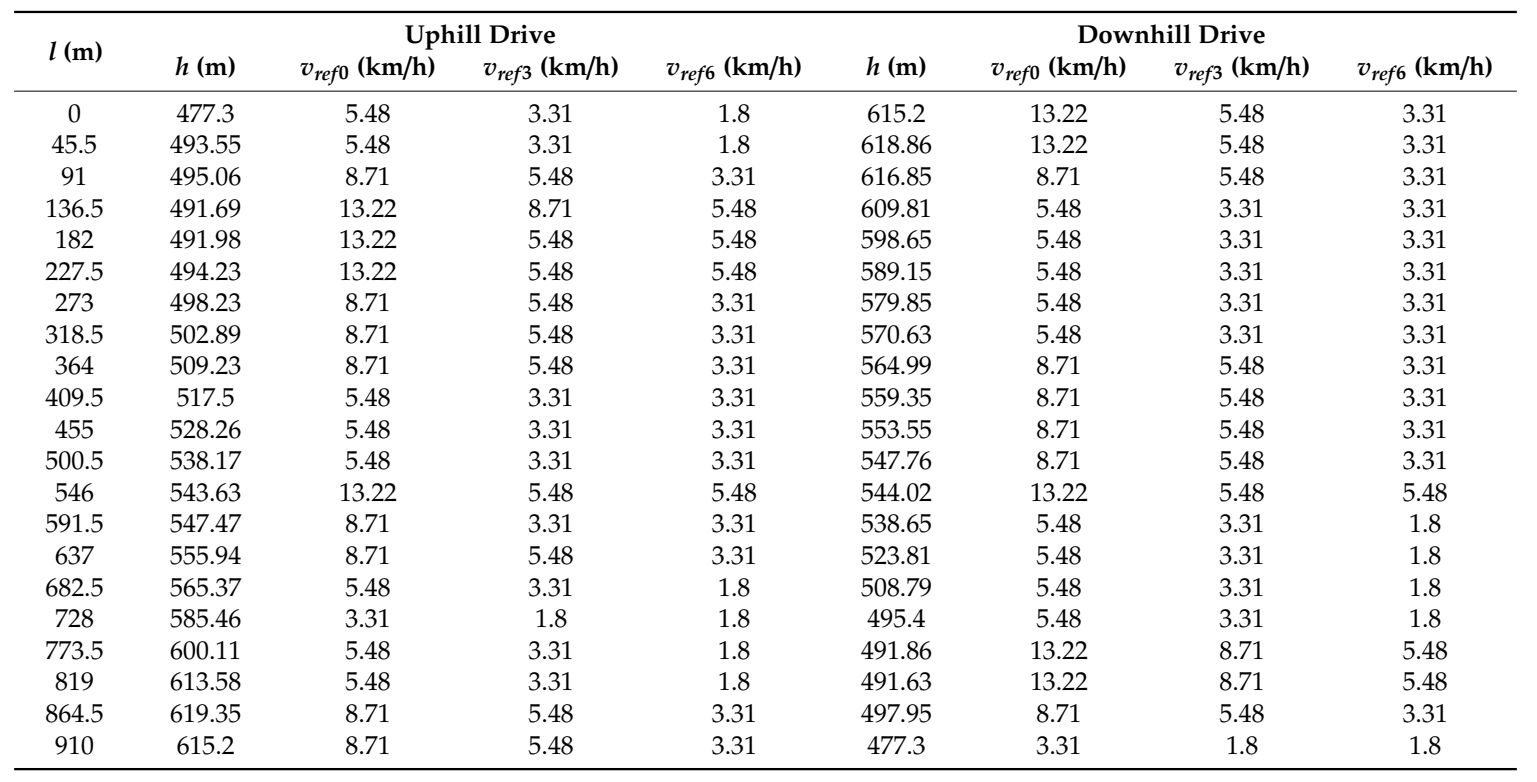

Logs can be skidded in both uphill and downhill driving scenarios, therefore, two different scenarios were made. In the A scenario, the felling site is located on the higher attitude, above the landing site, and in the B scenario, the felling site is located on the lower attitude, below the landing site. One driving cycle consists of unloaded travel, winching, and loaded travel, and according to [21], on an average skid trail distance of $900 \mathrm{~m}$ it is possible to complete 8.6 cycles in one working day in both A and B scenarios. Average measured load mass is around $4 \mathrm{t}$ [21], therefore $3 \mathrm{t}$ of logs were pulled in two thirds of the driving scenarios and $6 \mathrm{t}$ were pulled in one third of the driving scenarios. Fuel consumption for the conventional skidder is calculated by using the following expression:

$$
V_{f, \text { conv }}=V_{f, \text { conv } 0}+\left(\frac{1}{3} V_{f, \text { conv } 6}+\frac{2}{3} V_{f, \text { conv } 3}\right)+V_{f, \text { winch }}
$$

where $V_{f, \text { conv }}$ is fuel spent in one driving cycle of the conventional vehicle, $V_{f, c o n v 0,3,6}$ is that spent in driving with 0,3 , and $6 \mathrm{t}$ and $V_{f, \text { winch }}$ for winching. 
Expression for the hybrid vehicle is the same as above, but without winching:

$$
V_{f, \text { hev }}=V_{f, \text { hev } 0}+\left(\frac{1}{3} V_{f, \text { hev } 6}+\frac{2}{3} V_{f, \text { hev } 3}\right)
$$

\section{Control Variables Optimization of Skidder}

This section proposes the control variable optimization algorithm using the so-called cascade optimization procedure over a simplified (backward-looking) powertrain model with the battery state-of-charge as the only state variable. This optimization technique consists of dynamic programming (DP) for an initial (coarse) optimal solution search and the back propagation through time (BPTT) conjugate gradient-based optimization algorithm for the refinement of the initial optimal solution, which are applied sequentially as suggested in [8].

\subsection{Control Variables Optimization Problem of Hybrid Skidder}

Basic operating regimes of the hybrid skidder include all-electric and hybrid powertrain operation that depend on the battery $\mathrm{SoC}$. The optimization goal for operation in the so-called charge sustaining (CS) regime is to minimize the fuel consumption over the predefined time interval $0 \leq t \leq t_{f}$, while also satisfying transmission components constraints, battery state-of-charge bounds, and the boundary condition. The cost function for this optimization problem is:

$$
\min m_{f}=\int_{t_{0}}^{t_{f}} \dot{m}_{f}\left(\tau_{e}, \omega_{e}\right) \mathrm{dt}
$$

subject to the following inequality constraints:

$$
\begin{gathered}
S o C_{\min } \leq S o C \leq S o C_{\max } \\
0 \leq \omega_{e} \leq \omega_{e, \text { max }} \\
\omega_{m g, \min } \leq \omega_{m g} \leq \omega_{m g, \max } \\
0 \leq \tau_{e}\left(\omega_{e}\right) \leq \tau_{e, \max }\left(\omega_{e}\right) \\
\tau_{m g, \min }\left(\omega_{m g}\right) \leq \tau_{m g}\left(\omega_{m g}\right) \leq \tau_{m g, \max }\left(\omega_{m g}\right)
\end{gathered}
$$

and the final boundary constraint corresponding to the required final battery charge $S o C\left(t_{f}\right)$.

\subsection{Process Model}

For the purpose of optimization, the output shaft torque $\tau_{L}$ and the speed $\omega_{L}$ are defined as the known input variables to the backward model structure (vector $\left.\mathbf{v}(t)=\left[\tau_{L}(t) \omega_{L}(t)\right]^{T}\right)$. The engine torque $\tau_{e}$ and the gear selection signal $s_{\text {gear }}$ are defined as control inputs to be optimized (vector $\mathbf{u}(t)=\left[\tau_{e}(t)\right.$ $\left.\left.s_{\text {gear }}(t)\right]^{T}\right)$, where the variable $s_{\text {gear }}$ can assume five discrete values corresponding to five characteristic gear ratios (Table 2) [9]. Battery state-of-charge $(S o C)$ and fuel mass flow $\dot{m}_{f}$ are treated as model outputs (vector $\mathbf{y}(t)=\left[S o C(t) \dot{m}_{f}\right]^{T}$ ), with the battery $S o C$ being the only state variable within the model (i.e., $x=S o C$ ). Having this in mind, the process model is rewritten into the following state-space form used in optimization [8]:

$$
\begin{gathered}
\dot{x}=f(x, u, v), \\
y=\mathbf{g}(x, u),
\end{gathered}
$$

where the scalar function $f$, and similarly the vector function $\mathbf{g}$, are given by the battery model (7), as well as other model expressions and data maps given above.

\subsection{Outline of Cascade Optimization Approach}

For the purpose of control variables optimization, the utilization of the so-called cascade optimization approach previously developed in [8] is proposed in this paper. This approach consists of 
the initial optimization stage, carried out by using the dynamic programming (DP) algorithm, and the follow-up optimization (intended for refining of the initial DP optimization-based result) which is performed by the gradient-based BPTT algorithm (Figure 5). The DP-optimal outputs, which comprise the optimized control variables $\left(\tau_{e}(t)\right.$, and $\left.s_{g e a r}(t)\right)$ are included in the process model (Equation (10)) used for BPTT optimization as a priori known input variables (vector $\left.\mathbf{v}_{1}(t)=\left[\tau_{L}(t) \omega_{L}(t) \tau_{e}(t) s_{g e a r}(t)\right]^{T}\right)$. In order to avoid numerical issues associated with the calculation of the gradient based on discontinuous control variables (such as those that are integer-valued), only the differences of non-integer control variables are optimized by BPTT and used as a control input vector $\left(\mathbf{u}_{2}(t)=\left[\tau_{e}(t) 0\right]^{T}\right)$. The final optimal solution of the cascade approach is then represented as extrapolations of DP-optimized variables by means of BPTT-optimized expansions towards their optimum values $\left(\tau_{e, h}=\tau_{e}+\Delta \tau_{e} ; s_{\text {gear }, h}=s_{\text {gear }}\right)$.

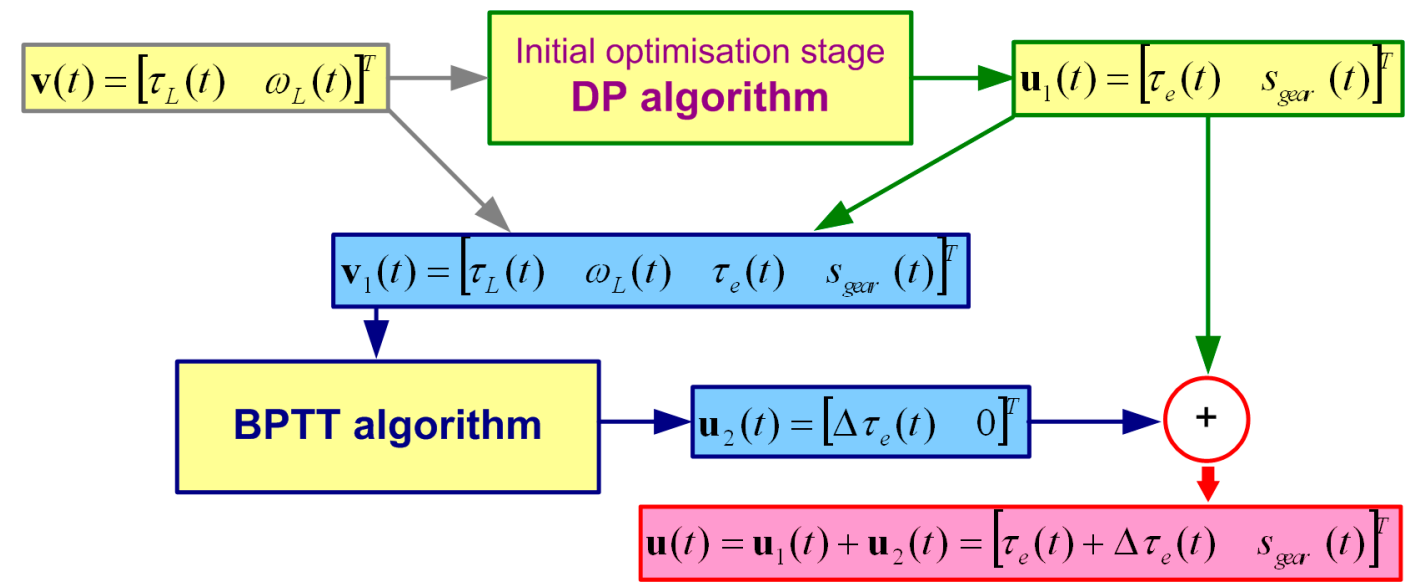

Figure 5. Functional diagram of cascade optimization approach.

In contrast to DP-based optimization, the BPTT algorithm is continuous in magnitude of the optimized variables, and could also use a higher-order integration method. Thus, the cascade optimization has several advantages over the approach that utilizes DP alone. In particular, the optimal solution precision can be improved by increasing the gradient algorithm's numerical precision, and a near-optimal solution can be found in a relatively short time by using dynamic programming with low grid density, whose results are subsequently refined by means of the gradient algorithm. Overall, this makes the cascade optimization approach a very promising tool for optimization studies that require high precision, while also being subject to limited optimization time [8].

\section{Optimization Results and Fuel Consumption Assessment}

Optimization results in the form of time spent driving, fuel used, and initial and final battery SoC from driving scenarios from Table 3 are shown in this section. Later on, two driving cycles that will be used for final calculations are defined.

\subsection{Optimization Results}

The optimization results in Table 4 were obtained for the proposed driving missions from Table 3 , where the first column shows route direction and different load mass $m_{t}$. The second column shows time needed for the proposed routes and loads. Column number three shows the fuel used with a conventional skidder $V_{f, c o n v}$, while columns four and five show initial and final battery state of charge $S_{o} C_{0}$ and $S o C_{t f}$, respectively. In the last column, the fuel used with hybrid skidder $V_{f, \text { hev }}$ is shown. Each driving mission also includes three different $S o C$ conditions, the first and third cases have the same initial and terminal values while the second case has a terminal value higher than the initial one. This higher terminal $\mathrm{SoC}$ value corresponds to the additional purposeful battery charging during the driving mission in order to ensure additional energy is stored in the battery (battery SoC) for forthcoming winching operations, which can deplete the battery charge by about $6 \%$ when average 
winching distances according to [23] are considered. Table 4 also contains fuel consumption results of the conventional vehicle for the same driving missions, as a benchmark.

Table 4. Optimization results.

\begin{tabular}{|c|c|c|c|c|c|}
\hline Route- $m_{t}(\mathrm{t})$ & Time (s) & $V_{f, \text { convi }}(\mathrm{L})$ & $\operatorname{SoC}_{0}(\%)$ & $\operatorname{SoC}_{t f}(\%)$ & $V_{f, h e v i}(\mathrm{~L})$ \\
\hline \multirow{4}{*}{ Uphill—6 } & \multirow{3}{*}{1122} & \multirow{3}{*}{3.16} & 59 & 59 & 3.06 \\
\hline & & & 59 & 65 & 3.23 \\
\hline & & & 65 & 65 & 3.06 \\
\hline & \multirow{4}{*}{794} & \multirow{3}{*}{2.23} & 59 & 59 & 1.94 \\
\hline \multirow[t]{3}{*}{ Uphill-3 } & & & 59 & 65 & 2.19 \\
\hline & & & 65 & 65 & 1.94 \\
\hline & & \multirow{3}{*}{1.28} & 59 & 59 & 0.99 \\
\hline \multirow[t]{3}{*}{ Uphill—-0 } & \multirow[t]{3}{*}{455} & & 59 & 65 & 1.37 \\
\hline & & & 65 & 65 & 0.99 \\
\hline & & \multirow{4}{*}{1.21} & 59 & 59 & 0.95 \\
\hline \multirow[t]{3}{*}{ Downhill—6 } & \multirow[t]{3}{*}{1090} & & 59 & 65 & 1.20 \\
\hline & & & 65 & 65 & 0.94 \\
\hline & & & 59 & 59 & 0.44 \\
\hline \multirow[t]{3}{*}{ Downhill-3 } & \multirow[t]{3}{*}{762} & \multirow[t]{2}{*}{0.74} & 59 & 65 & 0.73 \\
\hline & & & 65 & 65 & 0.49 \\
\hline & & \multirow{3}{*}{0.36} & 59 & 61 & 0.02 \\
\hline \multirow[t]{2}{*}{ Downhill-3 } & \multirow[t]{2}{*}{449} & & 59 & 65 & 0.26 \\
\hline & & & 65 & 67 & 0.02 \\
\hline
\end{tabular}

Figure 6 shows the time responses of input variables (demanded driveline torque $\tau_{L}$ and speed $\omega_{L}$ ) used within the optimization algorithm, and the optimized control vector obtained for the scenario from the first column in Table 4 , as well as the engine operating points. Figure 6 a shows the input $\mathbf{v}(t)=\left[\tau_{L}(t)\right.$ $\left.\omega_{L}(t)\right]^{T}$ of the backward model, derived from the driving cycle pre-defined vehicle velocity $v$ by using Equations (1) and (2). Optimized control variables of the hybrid skidder (ICE engine torque $\tau_{e, h}$ and operating mode $\left.s_{\text {gear }, h}\right)$ are shown in Figure $6 \mathrm{~b}$ together with conventional skidder variables $\left(\tau_{e, c}, s_{\text {gear }, c}\right)$. The results show that both skidders operate at the same selected gear throughout most of the operating cycle. However, the hybrid skidder can increase the engine torque over approximately half an operating cycle period when compared to that of the conventional one (blue line in Figure 6b), thus better utilizing the more efficient engine operating area associated with lower specific fuel consumption.
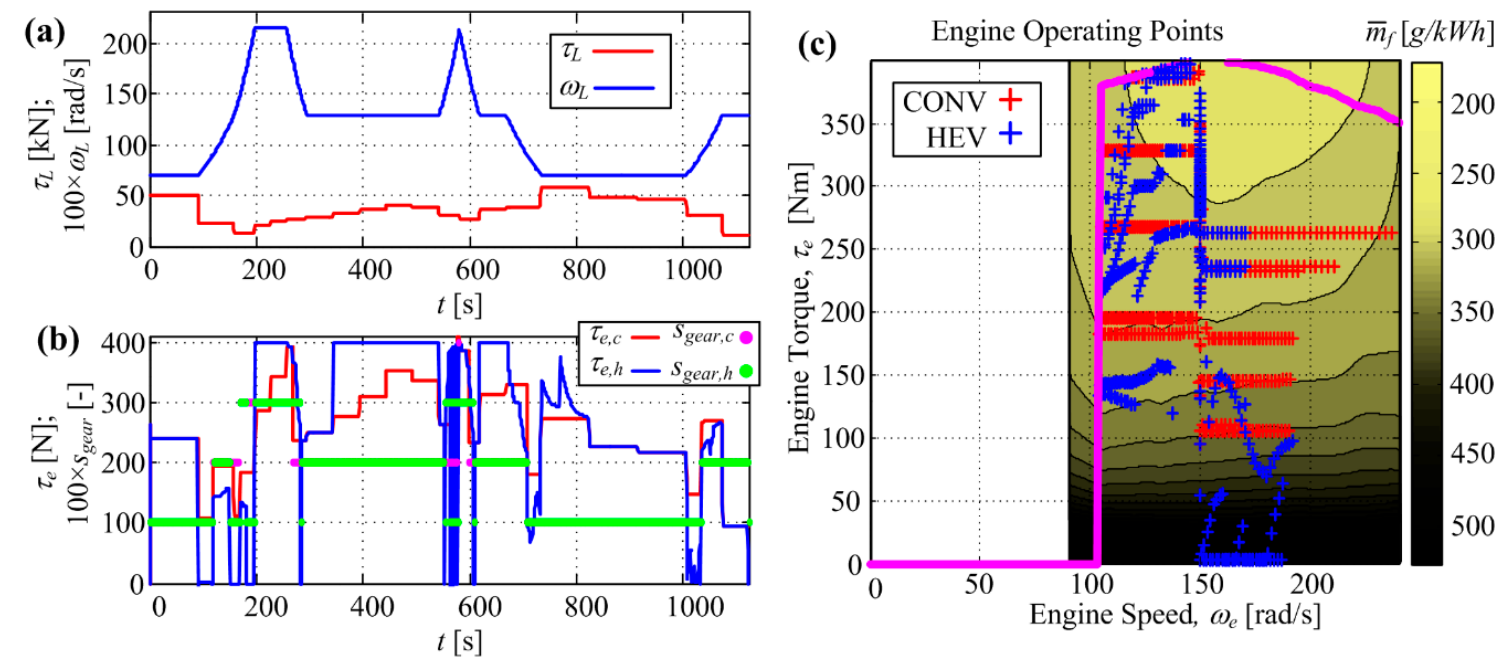

Figure 6. Backward model input variables (a), optimized control variables (b), and engine operating points (c). 
Output variables of the backward skidder model are shown in Figure 7 where final values of fuel consumptions for both skidders are given in Figure 7a, while the battery state of charge $50 \mathrm{C}$ is given in Figure $7 \mathrm{~b}$. The blue trace in Figure $7 \mathrm{~b}$ shows that the $S o C$ is maintained close to the desirable level (see Table 4). Fuel consumption of the hybrid skidder is slightly below that of the conventional one. Lower differences in fuel consumption are noticed in the very load-intensive scenario in which the conventional skidder becomes more efficient simply by operating at higher torque values, associated with lower specific fuel efficiencies (see above). This is indeed confirmed by other results in Table 4 that indicate that the hybrid skidder is indeed more efficient for lower loads.
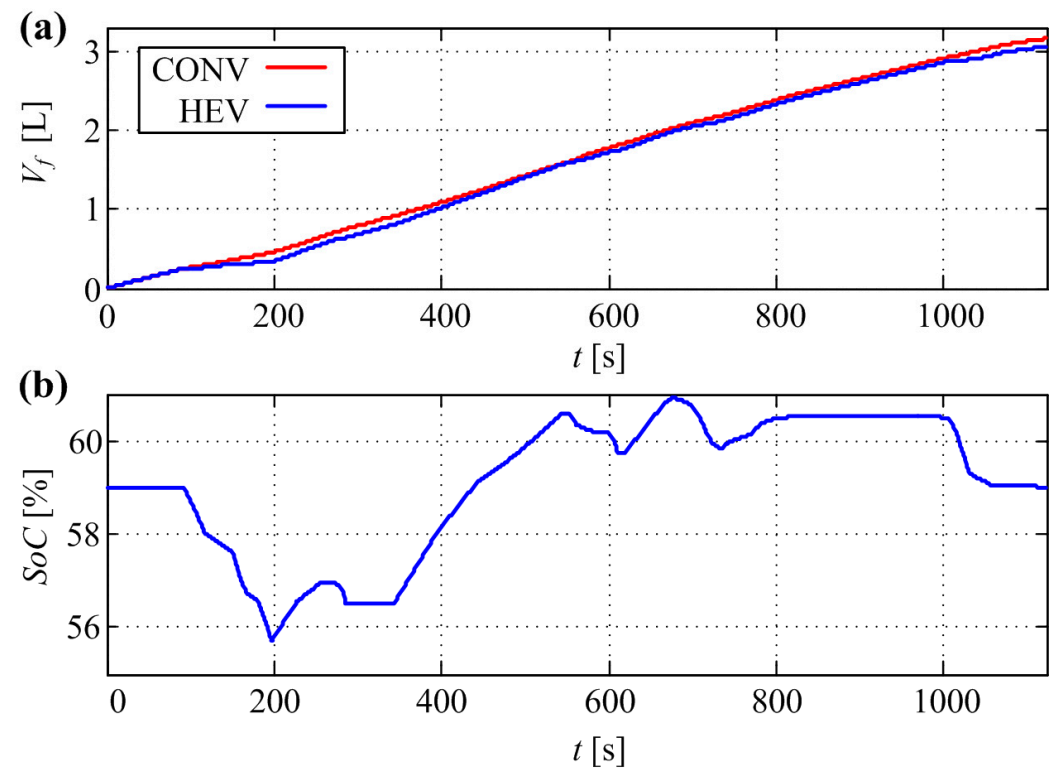

Figure 7. Backward model output variables: fuel consumption (a) and battery state of charge (b).

\subsection{Fuel Consumption}

There are two combinations of initial and final battery $S o C$ (Table 4) for every scenario. For every arrival at the felling site, because of winching, battery $\mathrm{SoC}$ drops by $6 \%$, and for arrival at the landing site, it remains unchanged. Thus, for every arrival at the felling site the final battery $S o C$ must be $65 \%$.

Fuel consumption for different driving scenarios of hybrid skidder is shown in Table 5 . Driving combinations of different initial and final SoCs are shown in the second row. From Table 5 it can be seen that the best option for scenario A is the second one (A2), where the skidder recharges the battery during downhill driving, where hybrid skidder uses $1.87 \mathrm{~L}$ of fuel compared to the $2.26 \mathrm{~L}$ used by the conventional skidder. In this way, fuel savings of $17.26 \%$ are achieved with the hybrid vehicle. In one workday, for winching and skid trail travel operations, the conventional skidder uses $19.44 \mathrm{~L}$ of fuel and the hybrid uses $16.1 \mathrm{~L}$ of fuel.

Table 5. Fuel consumption for different driving scenarios.

\begin{tabular}{cccc}
\hline Scenario & Uphill-Downhill & $V_{f, h e v}(L)$ & $V_{f, \text { conv }}(\mathrm{L})$ \\
\hline A1 & $59 \rightarrow 65-59 \rightarrow 59$ & 1.98 & \\
A2 & $65 \rightarrow 65-59 \rightarrow 65$ & 1.87 & 2.26 \\
B & $59 \rightarrow 59-59 \rightarrow 65$ & 2.57 & 2.98 \\
\hline
\end{tabular}

Slightly better results are achieved for the (B) option, where the skidder recharges the battery during downhill driving. Unloaded downhill driving is characterized with small, almost negligible consumption owing to fully electrical driving of the hybrid vehicle. The diesel engine is only used for starting and abrupt accelerations 
The B case scenario where the battery is charged during downhill driving is the only possible case, because for the other cases, battery $S o C$ oversteps the required terminal condition when it is set to the same value as the initial $S o C$ condition (for example for the required $65 \%$ terminal $S o C$, the battery is recharged to $67 \%$, as shown in Table 4). Therefore, other cases were not considered in further calculations. With the aforementioned scenario as listed in Table 5, fuel savings of $13.76 \%$ are achieved. For one working cycle in the B scenario, the hybrid skidder uses $2.57 \mathrm{~L}$ of fuel, where the conventional skidder uses $2.26 \mathrm{~L}$ of fuel. That translates to $25.63 \mathrm{~L}$ of fuel for the conventional and $22.1 \mathrm{~L}$ of fuel for the hybrid skidder that are used for skid trail travel and winching over a single workday.

\section{Results Discussion and Cost Assessments}

According to [24], for very shallow battery depth of discharge (DoD) (10\%), the battery cycle life is typically about 15,000 charge/discharge cycles. This life cycle value represents the expected utilization lifetime of the skidder battery before the degradation of its characteristics due to utilization becomes perceptible (i.e., its charge capacity drops below $80 \%$ of the nominal value [25] or its internal resistance increases by $100 \%$ [26]), which typically mandates a complete replacement of the battery energy storage system. The aforementioned $10 \% \mathrm{SoC}$ charge-discharge cycle approximately corresponds to one skidder's driving cycle, wherein winching discharges the battery by about $6 \%$ of the nominal charge, and the rest (4\% of the nominal charge) would be discharged during driving. With that said, it is likely that the battery would last for at least 15,000 driving cycles. Cumulative fuel consumption and fuel cost of the conventional and hybrid skidders are listed in Table 6. Skidders operate on many different attitudes and terrain slopes (uphill and downhill driving), so the fuel used for final comparison is the mean value of the A2 and B scenarios, which represent one driving cycle used in Table 6. It is expected that in the battery life span, the hybrid skidder could reduce fuel consumption by $6000 \mathrm{~L}$, which also corresponds to a reduction of $\mathrm{CO}_{2}$ of $15.9 \mathrm{t}$ and with the current diesel fuel price of $1.086 \mathrm{EUR} / \mathrm{L}$ [27], it translates to savings of 6515 EUR.

Table 6. Cumulative consumption, emissions, and costs.

\begin{tabular}{cccccc}
\hline Skidder Type & \multicolumn{2}{c}{ Fuel Used (L) } & \multicolumn{2}{c}{$\mathbf{C O}_{\mathbf{2}}$ Emissions (kg) } & Fuel Cost (EUR) \\
\hline & $\mathbf{1}$ Cycle & $\mathbf{1 5 , 0 0 0}$ Cycles & $\mathbf{1}$ Cycle & $\mathbf{1 5 , 0 0 0 ~ C y c l e s ~}$ & \\
\hline Conventional & 2.62 & 39,300 & 6.92 & 103,800 & 42,680 \\
Hybrid & 2.22 & 33,300 & 5.86 & 87,900 & 36,164 \\
Savings & 0.4 & 6000 & 1.06 & 15,900 & 6516 \\
Efficiency improvement (\%) & 15.27 & & & & \\
\hline
\end{tabular}

Diesel fuel and battery costs can change over time, hence the maximum acceptable battery cost can be estimated as [16]:

$$
c_{\text {batt }}=\frac{\left(V_{f, \text { conv }}-V_{f, h e v}\right) \cdot c_{f u e l} \cdot N_{c y c l e}}{E_{\text {batt }}}
$$

where $V_{f, c o n v}$ and $V_{f, h e v}$ are total fuel consumed in liters for the conventional and the hybrid skidders, respectively (see Table 5), $N_{\text {cycle }}$ is the number of cycles over one battery life cycle (chosen to be 15,000 ), $E_{\text {batt }}$ is the proposed battery capacity in $\mathrm{kWh}$, and $c_{f u e l}$ is the diesel fuel price in EUR/L.

According to Equation (14), while using data from Table 3 and taking into account the battery size, diesel fuel costs, and the number of cycles, the battery cost should not exceed $447 \mathrm{EUR} / \mathrm{kWh}$. For that maximum battery cost value, the only savings that can be achieved are in terms of $\mathrm{CO}_{2}$ reduction.

The average price of an Li-ion battery per kWh in 2019 was 156 EUR [28]. According to supplier data [29], the price for a single electromotor is 5000 EUR. Estimated costs of hybrid skidder components are shown in Table 7. Other accessory components needed for this kind of hybridization (cables, new clutch, etc.) are not included in this calculation. 
Table 7. Hybrid components' prices.

\begin{tabular}{cc}
\hline Component & Cost (EUR) \\
\hline Battery 1 kWh & 156 \\
Battery 15 kWh & 2340 \\
Electromotor 64 kW & 5000 \\
Total & 7340 \\
\hline
\end{tabular}

According to [30], the average number of operating days in one year for twelve different forest units in Croatia for the aforementioned EcoTrac 120 skidder is 151 days, which translates to 1208 operating hours. With battery and electromotor prices from Table 7 and diesel prices according to [27] it is possible to pay off the main hybrid drive components in 13 years and reduce $\mathrm{CO}_{2}$ emissions by $18.2 \mathrm{t}$ (1.4 $\mathrm{t}$ per year). It is worth mentioning that this pay-off time relates only to savings achieved with winching and skid trail driving, where the skidder does 8.6 full cycles in one day as mentioned before. In real life scenarios, the number of skidder's working days strongly depends on exploitation strategy, weather, work conditions, etc.

If an achieved efficiency improvement of $15.27 \%$ can be carried throughout all the skidder's operations, with average fuel consumption of $10.1 \mathrm{~L}$ per hour reported in [11] and 1208 operating hours in one year, the return of investment period is reduced to 44 months with $4.9 \mathrm{t}$ of $\mathrm{CO}_{2}$ emissions reduction per year.

As mentioned earlier, there are 121 EcoTrac $120 \mathrm{~V}$ skidders in Croatia, and by introducing the proposed hybrid system to a large number of skidders, the purchase price of the hybrid components would likely be lower due to bulk purchase discounts [29], so that the overall fuel savings and $\mathrm{CO}_{2}$ emission reduction potential can be better utilized.

\section{Conclusions}

The paper has presented a backward powertrain model of a skidder based on data presented in a previous paper from the same authors. The driving control variables were optimized by means of a cascade optimization approach combining DP and BPTT optimization algorithms in a sequential manner with the goal of minimizing the fuel consumption while satisfying transmission components constraints and the required state-of-charge bounds and boundary conditions. The optimization algorithm showed promising results. For most loads, initial and final $\mathrm{SoC}$ were honored, while simultaneously achieving fuel consumption reduction for the particular route. Higher consumption for the hybrid skidder was noticed in scenarios where the battery was recharged during driving. Two different driving scenarios for the case of loaded uphill and downhill drives were defined. Best cases from both these scenarios were used in the further assessment of the hybrid skidder, with their median values showing an efficiency improvement of $15.27 \%$. The proposed novel control variable optimization showed perceptible improvement in terms of fuel savings compared to the rather simple rule-based control presented in the previous paper from the same authors, while also maintaining sustainable battery $S o C$ levels throughout the whole working cycle. In this way, the proposed methodology systematically solves the problem of fuel consumption optimization for the particular skidder hybrid powertrain topology, while also maintaining the battery state-of-charge within prescribed margins. This is beneficial from the standpoint of energy reserve for emergency situations and also from the standpoint of maximization of the useful life of the battery (i.e., by preventing deep battery discharges).

The analysis has also shown that with an approximate battery life of 15,000 cycles it is possible to save 6516 EUR worth in fuel, as well as to achieve proportional reductions of $\mathrm{CO}_{2}$ emissions. With the listed hybrid components prices and average number of the skidder's operating hours, it is possible to pay off the main hybrid components in 13 years of continuous work under the considered simulation scenario assuming 151 effective 8-hour long workdays, or 44 months if the achieved powertrain efficiency can be carried throughout all the skidder's operations. 
It is worth mentioning that this efficiency improvement refers only to skid trail driving and winching operations. More accurate numbers and results could be obtained if this control variable optimization procedure was carried out throughout the whole skidding process, characterized by additional operating regimes. Therefore, the next step in this research would be to carry out the analysis using accurate real-life recorded terrain data that would contain better resolution of the terrain slope profile and vehicle speed, and actual winch loads encountered in real-life operation.

Author Contributions: Conceptualization, J.K. and M.C.; methodology, J.K. and M.C.; validation, J.B., D.P., Ž.Š., and M.Š.; writing—original draft preparation, J.K.; writing—review and editing, D.P.; visualization, M.C.; software M.C.; supervision, Ž.Š. and M.Š.; project administration, M.Š. All authors have read and agreed to the published version of the manuscript.

Funding: It is gratefully acknowledged that this research has been supported by the EU European Regional Development Fund under the grant KK.01.1.1.04.0010 (HiSkid).

Acknowledgments: We would like to pay our gratitude and our respects to our colleague, Joško Petrić. After helping to initiate this research, Joško Petrić passed away in July of 2019. He was a tenured professor at the Department of Robotics and Production System Automation at the Faculty of Mechanical Engineering and Naval Architecture, University of Zagreb, Croatia.

Conflicts of Interest: The authors declare no conflict of interest.

\section{References}

1. Francx, L.; Van Hyfte, A. Study in View of the Revision of Directive 97/68/EC on Non-Road Mobile; Machinery (NRMM); Publications Office of the EU: Luxembourg, 2014.

2. Abbas, D.; Handler, R. Life-cycle assessment of forest harvesting and transportation operations in Tennessee. J. Clean. Prod. 2017, 176, 512-520. [CrossRef]

3. Shen, R.; Zhang, X.; Zhou, C. Study on Drive System of Hybrid Tree Harvester. Sci. World J. 2017, 2017, 8636204. [CrossRef]

4. Li, T.; Liu, H.; Wang, H.; Yao, Y. Hierarchical predictive control-based economic energy management for fuel cell hybrid construction vehicles. Energy 2020, 198, 117327. [CrossRef]

5. Feng, Y.; Dong, Z. Optimal Control of Natural Gas Compression Engine Hybrid Electric Mining Trucks for Balanced Fuel Efficiency and Overall Emission Improvement. Energy 2019, 189, 116276. [CrossRef]

6. Yang, Y.; Hu, X.; Pei, H.; Peng, Z. Comparison of power-split and parallel hybrid powertrain architectures with a single electric machine: Dynamic programming approach. Appl. Energy 2016, 168, 683-690. [CrossRef]

7. Guzzella, L.; Sciarretta, A. Vehicle Propulsion Systems-Introduction to Modeling and Optimization, 2nd ed.; Springer: Berlin/Heidelberg, Germany, 2007.

8. Cipek, M.; Kasać, J.; Pavković, D.; Zorc, D. A novel cascade approach to control variables optimization for advanced series-parallel hybrid electric vehicle power-train. Appl. Energy 2020, 276, 115488. [CrossRef]

9. Karlušić, J.; Cipek, M.; Pavković, D.; Benić, J.; Šitum, Ž.; Pandur, Z.; Šušnjar, M. Simulation Models of Skidder Conventional and Hybrid Drive. Forests 2020, 11, 921. [CrossRef]

10. Hittner Tractors-Croatia. Available online: http://hittner.hr/tractors (accessed on 5 November 2020).

11. Tomljanović, K. Skidder Fuel Consumption. Master's Thesis, University of Zagreb, Zagreb, Croatia, 2019; pp. 18-26. (In Croatian).

12. Knežević, I. Preoblikovanje razvodnika snage šumskog traktora za pogon svih kotača i vitla (Reshaping Power Distributor of Skidder to Drive all the Wheels and Winches). Master's Thesis, University of Zagreb, Zagreb, Croatia, 2010; pp. 12-16. (In Croatian).

13. Certificate, D914L06, DEUTZ AG, DE-51057, Cologne, Germany. 2004.

14. Trzciński, G.; Moskalik, T.; Wojtan, R. Total Weight and Axle Loads of Truck Units in the Transport of Timber Depending on the Timber Cargo. Forests 2018, 9, 164. [CrossRef]

15. EVO Axial Flux Electric Motor-AF 130 Model. Available online: https://www.neweagle.net/support/wiki/ ProductDocumentation/EV_Software_and_Hardware/Electric_Motors/AVID/EVO-AF130.pdf (accessed on 5 November 2020). 
16. Cipek, M.; Pavković, D.; Kljaić, Z.; Mlinarić, T.J. Assessment of battery-hybrid diesel-electric locomotive fuel savings and emission reduction potentials based on a realistic mountainous rail route. Energy 2019, 173, 1154-1171. [CrossRef]

17. Đuka, A.; Pentek, T.; Horvat, D.; Poršinsky, T. Modelling of Downhill Timber Skidding: Bigger Load-Bigger Slope. Croat. J. For. Eng. 2016, 37, 139-150.

18. Gregov, G. A Contribution to Research in Modeling of Hydrostatic Transmission in a Forestry Vehicle. Ph.D. Thesis, University of Rijeka, Rijeka, Croatia, 2012; p. 132. (In Croatian).

19. Bin, Y.; Li, Y.; Feng, N. Nonlinear Dynamic Battery Model with Boundary and Scanning Hysteresis. In Proceedings of the ASME 2009 Dynamic Systems and Control Conference 2009, Hollywood, CA, USA, 12-14 October 2009.

20. Barlow, T.J.; Latham, S.; McCrae, I.S.; Boulter, P.G. A Reference Book of Driving Cycles for Use in the Measurement of Road Vehicle Emissions; Published Project Report PPR354; Transport Research Laboratory TRL: Crowthorne, UK, 2009.

21. Zečić, Ž.; Papa, I.; Vusić, D.; Benković, Z.; Marenče, J. Productivity of tractor Ecotrac $120 \mathrm{~V}$ timber skidding in hilly area of Central Croatia. Nova Mehanizacija Šumarstva 2019, 40. (In Croatian) [CrossRef]

22. Karlušić, J.; Cipek, M.; Pavković, D.; Šitum, Ž.; Benić, J.; Šušnjar, M. Benefit Assessment of Skidder Powertrain Hybridization, Digital. In Proceedings of the 4th South East Europe (SEE) Sustainable Development of Energy Water and Environment Systems (SDEWES) conference, Sarajevo, Bosnia and Herzegovina, 28 June-2 July 2020.

23. Horvat, D.; Zečić, Ž.; Šušnjar, M. Morphological characteristics and productivity of skidder ECOTRAC 120 V. Croat. J. For. Eng. 2007, 28, 11-25.

24. Available online: https://batteryuniversity.com/learn/article/how_to_prolong_lithium_based_batteries (accessed on 5 November 2020).

25. Shahriari, M.; Farrokhi, M. Online state-of-health estimation of VRLA batteries using state-of-charge. IEEE Trans. Ind. Electron. 2013, 60, 191-202. [CrossRef]

26. Kim, J.; Cho, B.H. State-of-charge estimation and state-of-health prediction of a Li-ion degraded battery based on an EKF combined with a per-unit system. IEEE Trans. Veh. Technol. 2011, 60, 4249-4260. [CrossRef]

27. Available online: https://autotraveler.ru/en/croatia/trend-price-fuel-croatia\#.X6XO6WhKguU (accessed on 5 November 2020).

28. Available online: https://about.bnef.com/blog/battery-pack-prices-fall-as-market-ramps-up-with-marketaverage-at-156-kwh-in-2019/ (accessed on 5 November 2020).

29. Available online: https://www.avid.com/ (accessed on 15 April 2020).

30. Rašić, I. Analysis of skidder utilization in Forestry. Master's Thesis, University of Zagreb, Zagreb, Croatia, 2019; pp. 24-30. (In Croatian)

Publisher's Note: MDPI stays neutral with regard to jurisdictional claims in published maps and institutional affiliations.

(C) 2020 by the authors. Licensee MDPI, Basel, Switzerland. This article is an open access article distributed under the terms and conditions of the Creative Commons Attribution (CC BY) license (http://creativecommons.org/licenses/by/4.0/). 